\section{Influence of knowledge management on increasing service innovation at Dental Hospital Hasanuddin University 2020}

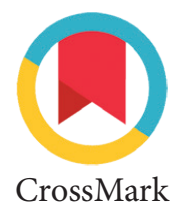

Alqarama M. Thalib, ${ }^{1 *}$ Andi I. Sidin, ${ }^{2}$ Syamsuddin ${ }^{3}$

\title{
Abstract
}

Objective: The aim of analyze and improve the service innovation at Hasanuddin University Dental and Oral Hospital through the use of the knowledge management system.

Material and Methods: The instrument used in data collection was a questionnaire. There are two variables in this study, namely the independent variable is knowledge generation, knowledge storage, knowledge diffusion, knowledge application and the dependent variable is service innovation.

Results: An effect knowledge generation on increasing service innovation ( $p=0.000$ ) with an $R$ coefficient value square of 0.392 , there was an effect of knowledge storage on increasing service innovation. $(p=0.000)$ with an $R$ coefficient value square of 0.285 there is an effect of knowledge diffusion on increasing service innovation ( $p=0.000$ ) with an $R$ coefficient value of 0.374 , and there is an effect of knowledge application on increasing service innovation $(p=0.000)$ with an $R$ coefficient value. amounting to 0.176 . It is recommended that the hospital management pay attention to and optimize the knowledge application at the Hasanuddin University Dental and Oral Hospital.

Conclusion: This study is that there is an effect of knowledge generation, knowledge storage, knowledge diffusion, and knowledge application on improving service innovation at Dental Hospital Hasanuddin University.
${ }^{1}$ Department of Dental Materials, Faculty of Dentistry, Hasanuddin University and Graduate Institute of Dental Science, College of Dentistry, China Medical University, Taichung, Taiwan

${ }^{2}$ Department of Hospital Management, Faculty of Public Health, Hasanuddin University, Makassar, Indonesia

${ }^{3}$ Department of Accounting, Faculty of Economics and Business, Hasanuddin University, Makassar, Indonesia

*Correspondence to:

Alqarama M. Thalib, Department of Dental Materials, Faculty of Dentistry, Hasanuddin University and Graduate Institute of Dental Science, College of Dentistry, China Medical University, Taichung, Taiwan qarafkg09@gmail.com

Received: 5 November 2020

Revised: 4 December 2020

Accepted: 6 January 2021

Available Online: 1 April 2021

Keywords: Knowledge application, Knowledge diffusion, Knowledge generation, Knowledge management, Service innovation Cite this Article: Thalib AM, Sidin Al, Syamsuddin. 2021. Influence of knowledge management on increasing service innovation at Dental Hospital Hasanuddin University 2020. Journal of Dentomaxillofacial Science 6(1): 45-50. D0l: 10.15562/jdmfs.v6i1.1175

\section{Introduction}

The development of the health service business world is growing so rapidly causing competition between hospitals is getting tighter, so that the hospital is required to increase innovation in order to compete. In the era of globalization of the business market, it requires every hospital to always try to improve the quality of its services, this also applies to service companies though and both in terms of improving the quality of their services. Innovation is very important for hospital management to do. Innovation is a term that has been used widely in various fields.

Innovation is usually closely related to an environment that is characterized by dynamic and developing. Innovation is an idea, practice, or object that is considered new by individuals from one adoption unit to another. Therefore, it is important for health service providers, namely hospitals, in creating new ideas in every health service activity. ${ }^{1}$

The health service process is a core service or primary service in hospital services which is determined by the human resources in it. ${ }^{1} \mathrm{~A}$ hospital that has a human resource-intensive character because it uses many types and various qualifications of human resources. Therefore, the hospital must optimize the knowledge of each human resource in order to provide the best service to patients so that a system is needed to manage all knowledge / information of every employee in the hospital which is called knowledge management.

Knowledge management is a systematic process used by organizations and individuals to seek, store, retrieve, share, adapt and use knowledge to promote organizational goals. ${ }^{2}$ show thatactivities knowledge management have a direct impact on innovation and organizational performance, and indirectly can increase the ability to innovate.

Previous research has also argued that managing knowledge effectively increases a firm's innovation capacity. ${ }^{3,4}$ This is consistent with the findings that practices knowledge management have an influence on innovation performance. ${ }^{5}$ Practices Knowledge management are a series of strategies, initiatives, and activities that companies use to generate, transfer, apply and store knowledge. ${ }^{4}$

Justifies the influence ofpractices knowledge management (generation, diffusion and storage) on hospital innovation, ${ }^{6}$ but also explores how the application of knowledge helpspractices knowledge management otherto increase innovation in hospital services. In addition to the direct relationship betweenpractices knowledge management and 
innovation,practices knowledge management also mediate the relationship between many other variables and innovation.?

The development of the Dental Hospital Hasanuddin University into a professional and growing hospital must be in line with the ability to adapt to environmental demands. As a Dental Hospital that has been fully accredited and has received status as a Main Teaching Hospital, the hospital must actively develop new knowledge to solve existing problems.

The main problem at the Dental Hospital Hasanuddin University is the medical service products at the Dental Hospital Hasanuddin University due to the lack of new service products issued by the Dental Hospital Hasanuddin University, from the data for 2017-2019 only private care services have become new services at Dental Hospital Hasanuddin University since November 2019 apart from the product services that are a prerequisite for accreditation of Dental Hospital Hasanuddin University.

Dental Hospital Hasanuddin University which has been fully accredited since 2019 should develop and innovate to improve service products to improve service quality. BPJS Kesehatan has also worked together from 2019, thus increasing the total number of patients significantly from the previous year at the Dental Hospital Hasanuddin University, but this is not offset by new service products that can more broadly reach the interests of the people of South Sulawesi.

Even though the patient visit data for the last 3 years is very dynamic, where in 2018 there were 9093 visits on outpatient care to 32,936 visits in 2019. This was also greatly influenced after the entry of BPJS Health at the Dental Hospital, after that until June 2020 it decreased significantly by only 7655 which was greatly affected by the Covid Pandemic -19, Dental Hospital Hasanuddin University must quickly respond to this pandemic condition by innovating the latest breakthroughs so that the number of visits can increase so that it can increase the amount of revenue of Dental Hospital Hasanuddin University where the revenue data for 2018 is 2.6 billion to 4.7 billion in 2019 .

Pandemic effect in the year 2020 is almost over However, hospital income will decrease significantly due to the significantly reduced number of patient visits. Therefore, Service Innovation must be given more attention so that hospital problems can be resolved.

Based on this phenomenon, it can be seen that the fundamental problem of the importance of service innovation must be the focus of attention of the hospital and the lack of service innovation carried out by Dental Hospital Hasanuddin
University in the form of the latest service products must be considered to improve the quality of health services to patients. The purpose of this study was to analyze the effect of knowledge management on improving service innovation at Dental Hospital Hasanuddin University.

\section{Material and Methods Location and research design}

This research was conducted at Hasanuddin University Dental Hospital. This type of research is a quantitative study using an observational study with aapproach Cross Sectional Study.

\section{Population and sample}

The population in this study were all employees who worked at the Dental Hospital Hasanuddin University. The sample of this research is 51 employees who work in Haji General Hospital. The sampling technique in this study is the stratified random sampling.

\section{Data collection methods}

The instrument used in data collection was a questionnaire. There are two variables in this study, namely the independent variable is knowledge generation, knowledge storage, knowledge diffusion, knowledge application and the dependent variable is service innovation. The measurement used in the data processing is to use thescale Likert.

\section{Data analysis}

The data obtained will be analyzed using the SPSS program in a computer device, then processed by distribution through univariate analysis, bivariate analysis, and multivariate analysis. Univariate analysis was conducted to obtain an overview of the research problem by describing each variable used in the study and the characteristics of the respondent. Univariate analysis consisted of descriptive characteristics of respondents and descriptive analysis of variables. Bivariate analysis was conducted to see the relationship between the independent variable and the dependent variable. The statistical test used was thetest chi square. Multivariate analysis was conducted to determine the influence of the independent variable on the dependent variable with the statistical test used, namely the linear regression test.

\section{Results}

Table 1 shows the frequency distribution based on the characteristics of the sample at the study location. Most of the respondents at the Hasanuddin University Dental and Oral Hospital are at the age 
Table 1 Frequency Distribution of general characteristics of respondents at Dental Hospital Hasanuddin University

\begin{tabular}{|c|c|c|c|c|}
\hline \multicolumn{2}{|c|}{ Characteristics of Respondents } & \multirow{2}{*}{$\frac{\text { Number (n) }}{28}$} & \multirow{2}{*}{ Percentage (\%) } & \multirow[t]{2}{*}{ Total } \\
\hline \multirow{3}{*}{ Age } & 20-35 years & & & \\
\hline & $36-45$ years & 16 & 31.4 & \multirow[t]{2}{*}{51} \\
\hline & $>45$ years & 7 & 13.7 & \\
\hline \multirow{2}{*}{ Gender } & Male & 17 & 33.3 & \multirow{2}{*}{51} \\
\hline & Female & 34 & 66.7 & \\
\hline \multirow{4}{*}{$\begin{array}{l}\text { Working } \\
\text { period }\end{array}$} & 1-2 years & 9 & 17.6 & \multirow{4}{*}{51} \\
\hline & 3-4 years & 13 & 25.5 & \\
\hline & $5-6$ years & 8 & 15.7 & \\
\hline & $>6$ years & 21 & 41.2 & \\
\hline \multirow{4}{*}{$\begin{array}{l}\text { Last } \\
\text { education }\end{array}$} & High school / Equivalent & 3 & 5.9 & \multirow{4}{*}{51} \\
\hline & Diploma & 12 & 23.5 & \\
\hline & $\mathrm{S} 1 / \mathrm{S} 2$ & 17 & 33.4 & \\
\hline & Others & 19 & 37.2 & \\
\hline \multirow{3}{*}{ Civilstatus } & servant & 21 & 41.2 & \multirow{3}{*}{51} \\
\hline & Non PNS & 30 & 58.8 & \\
\hline & Others & 0 & 1.7 & \\
\hline
\end{tabular}

Table 2 Distribution of knowledge generation, knowledge storage, knowledge diffusion, knowledge application and service innovation

\begin{tabular}{lcc}
\hline & \multicolumn{2}{c}{ Percentage } \\
\cline { 2 - 3 } Research Variables & N & $\%$ \\
\hline Knowledge Generation & 43 & 83.2 \\
$\quad$ Good & 8 & 15.7 \\
$\quad$ Bad & & \\
Knowledge Storage & 42 & 82.4 \\
$\quad$ Good & 9 & 17.6 \\
$\quad$ Bad & & \\
Knowledge Diffusion & 42 & 82.4 \\
$\quad$ Good & 9 & 17.6 \\
$\quad$ Bad & & \\
Knowledge Application & 44 & 86.3 \\
$\quad$ Good & 7 & 13.7 \\
$\quad$ Bad & & 78.4 \\
Service Innovation & 40 & 21.6 \\
$\quad$ Good & 11 & \\
$\quad$ Bad & & \\
\hline
\end{tabular}

level of 20-35 years as many as 28 respondents (54.9\%) Judging from their gender, most of the respondents were female, namely 34 respondents $(66.7 \%)$. Based on the length of work, namely $>6$ years as many as 21 respondents $(41.2 \%)$ with the highest level of education are others in this case dentists and doctoral specialists, namely
19 respondents (37.2\%) and for employment status, namely non civil servants as many as 30 respondents (58.8\%).

Table 2 explains the percentage of respondents' assessment of the research variables. The results of research at the Hasanuddin University Dental and Oral Hospital showed that for the variable knowledge generation that stated good was $84.3 \%$ of employees and those who said it was bad were $15.7 \%$ of employees, the variable knowledge storage which said it was good was $82.4 \%$ of employees and those who said it was good. $17.6 \%$ of employees stated that they were bad, the variable knowledge diffusion which stated that was good was $82.4 \%$ of the employees and those who said it was bad were $17.6 \%$ of the employees, the variable knowledge application which said it was good was $86.3 \%$ of the employees and those who said it were bad were, $7 \%$ of employees and service innovation variables that stated good were $78.4 \%$ of employees and $21.6 \%$ of employees said they were bad.

Table 3 shows the relationship between the independent and dependent variables. The results of the bivariate analysis showed that there was an influence ofvariables knowledge generation on the innovation of services Dental Hospital Hasanuddin University with a value of $\mathrm{p}=0.000$, variables knowledge storage on service innovations at Dental Hospital Hasanuddin University with a value of $\mathrm{p}=0.000$, variable knowledge diffusion on innovation. Services Dental Hospital Hasanuddin University with a value of $\mathrm{p}=0.000$, variable knowledge application of service innovations at Hasanuddin University Dental and Oral Hospital with a value of $p=0.000<0.05$.

According to the results of this study, it explains that knowledge management consists of variable knowledge. generation, knowledge storage, knowledge diffusion, and knowledge applications have an effect on the innovation of the services Dental Hospital Hasanuddin University.

The variable knowledge generation has a determination coefficient of $\mathrm{R}$ square of 0.392 which means $39.2 \%$ variation in the innovation variable The service can be influenced by the knowledge generation variable, the variable knowledge storage has an coefficient of determination square of 0.285 which means that $28.5 \%$ of the variation in the service innovation variable can be influenced by the knowledge storage variable, the variable knowledge diffusion has an coefficient of determination square of 0.374 which means $37,4 \%$ of the variation in the variable service innovation the variable knowledge diffusion and variable application of knowledge has a coefficient of determination $\mathrm{R}$ square of 0.176 which means that $17.6 \%$ of the variation in the 
Table 3 Comparison of Sig. to test the relationship between knowledge generation, knowledge storage, knowledge diffusion, and knowledge applications to improve service innovation

\begin{tabular}{|c|c|}
\hline Dimensions / Variables & $\begin{array}{c}\text { Value Sig. } \\
\text { Dental Hospital } \\
\text { Hasanuddin University }\end{array}$ \\
\hline $\begin{array}{l}\text { Knowledge Generation for service } \\
\text { innovation }\end{array}$ & 0.000 \\
\hline Knowledge Storage for service innovation & 0.000 \\
\hline Knowledge Diffusion for service innovation & 0.000 \\
\hline $\begin{array}{l}\text { Knowledge Generation for service } \\
\text { innovation }\end{array}$ & 0.000 \\
\hline
\end{tabular}

variable service innovations can be affected by variables knowledge application.

According to the results of this study indicate that the variable knowledge generation that has the greatest influence on improving service innovation at Hasanuddin University Dental and Oral Hospital in 2020 and the variable knowledge application which has the least effect on improving service innovation at the Dental Hospital Hasanuddin University in 2020.

\section{Discussion}

Based on the results of statistical analysis, it is known that knowledge management which consists of variable knowledge generation, knowledge storage, knowledge diffusion and knowledge applications has an influence on service innovation at the Dental Hospital Hasanuddin University.

Previous research has argued that managing knowledge effectively increases a firm's innovation capacity Donate et al. ${ }^{4}$ This is consistent with the findings of Darroch et al. ${ }^{5}$ thatpractices knowledge management have an influence on innovation performance. Donate et al. ${ }^{4}$ also show thatpractices knowledge management (exploration and exploitation) have the capacity to improve performance in the form of innovative products.

Knowledge generation is an organizational process for creating knowledge Wang et al. ${ }^{8}$ The creation process is the process of identifying existing knowledge in the company, as well as efforts to generate new knowledge from the learning process. The results of research at Dental Hospital Hasanuddin University obtained that most employees who have good Knowledge Generation will have good service innovation. Variable Knowledge generation which has the greatest influence compared to other variables.

The questions with the highest positive responses (answers strongly agree and agree) were questions about the process of obtaining information about the latest services in the hospital at $94.2 \%$, while the lowest positive response was $62.7 \%$ were questions about the process for comparing performance with other employees. This is related to the value of competitive advantage of each employee to improve performance in health services by continuing to develop knowledge and skills possessed.

Knowledge generation or knowledge creation can be defined as a process by which companies acquire knowledge, either from outside the company or internally McCann et al. ${ }^{9}$ The aim is to acquire new and better knowledge that helps organizations improve competitiveness Williams et al. ${ }^{10}$

In line with previous research knowledge generation has an important role in supporting company performance Donate et al. ${ }^{5}$ this article provides empirical evidence of the mediating effect of practices knowledge generation in the relationship between knowledge-oriented leadership and innovation performance. Xie et al. ${ }^{11}$ found that knowledge acquisition has a significant positive impact on the radical innovation of a company.

Knowledge storage as a class of procedures and systems for storing and managing knowledge. These are often IT-based systems that support and enhance the storage and retrieval of operational knowledge Alegre et al. ${ }^{12}$ The results of the research at Dental Hospital Hasanuddin University showed that most employees who have good knowledge storage will have good service innovation.

The question with the highest positive response (answers strongly agree and agree) is the question about the process to protect information from theft by parties outside the hospital by $96 \%$, while the lowest positive response of $52.9 \%$ is a question about whether or not there are incentives that encourage protect information. This shows the high commitment of employees to be able to safeguard protected information in the hospital, including patient information.

A good distribution of innovation shows that at other educational levels, namely Masters and Specialist Doctors, the distribution is greater for good service innovation, this shows that with a high level of education employees can run good knowledge storage and they have a good view of service innovation.

This is in accordance with previous research Alegre et al. ${ }^{12}$ described knowledge storage as a class of procedures and systems for storing and managing knowledge. These are often IT-based systems that support and enhance the storage and retrieval of operational knowledge.

This knowledge takes many forms, including codified human knowledge, expert systems, written 
documentation, documented procedures, and tacit knowledge processes acquired by individuals and individual networks Donate et al. ${ }^{5}$ Yung et al. ${ }^{13}$ in their research found that knowledge storage affects innovation performance.

In addition to the high commitment of employees to protect information, the incentive to protect information is one of the things that causes good knowledge storage at Dental Hospital Hasanuddin University. Incentives have a positive and significant effect on employee performance, here it can be seen that by giving more appropriate incentives, employees will be more professional by working seriously and making various efforts to achieve better work results so that their performance can be further increased.

To improve the protection of information from the hospital by health workers, it is necessary to get special attention from the leadership of the Dental Hospital Hasanuddin University through the provision of appropriate incentives to health workers, including non-PNS employees, which are quite large in number.

Knowledge diffusion describes a process that facilitates the distribution of knowledge from one place, person or possession to another Hamdoun et al. ${ }^{14}$ The results of the research at Dental Hospital Hasanuddin University showed that most employees who have good Knowledge Diffusion will have good service innovation.

The statement for the variable knowledge diffusion at Dental Hospital Hasanuddin University, based on the research results, the question with the highest positive response (answers strongly agree and agree) is a question about whether or not there is a mechanism to encourage employees to share information with $96.1 \%$, while the lowest $78.4 \%$ positive response is a question about whether or not there is a codification system of information.

The information codification system is needed for the protection of personal data and hospital agencies, so the above needs special attention from the leadership of Dental Hospital Hasanuddin University through the procurement of an information codification system and the socialization of the system to employees.

This is consistent with previous research which says that knowledge diffusion is one of the fundamental aspects of knowledge management because the main purpose of this knowledge diffusion is to ensure that the available knowledge can be channeled and applied to the benefit of the organization. The process consists of gathering, organizing and conversing from one person to another about knowledge Cheng et al..$^{15}$ The fundamental objective is to use available knowledge to improve group performance Abou. ${ }^{16}$

The health sector is highly dependent on knowledge in daily activities, and especially, the delivery of health services depends on the collaboration of various partners who have to share knowledge. For this purpose, medical knowledge must be available and easily accessible to all who need it, therefore it is important for staff in the hospital to collaborate and share knowledge so as to achieve optimal health services.

Boateng et al. ${ }^{17}$ describe the application of knowledge as a process in an organization that enables an organization to use and enhance knowledge in ways that improve its operations, develop new products and generate new knowledge assets.

The results of the research at Dental Hospital Hasanuddin University showed that most employees who have good Knowledge Application will have good service innovation. The question with the highest positive response (answers strongly agree and agree) is the question about the process for applying information learned from experience of $94.2 \%$, while the lowest positive response of $80.4 \%$ is questions about the process for using information in development. new products / services.

This variable knowledge application has the lowest influence compared to other variables; therefore, the hospital must pay attention to the implementation of knowledge management at Dental Hospital Hasanuddin University because by implementing knowledge management it can solve problems that are owned by the hospital.

Previous research said Knowledge Application has a mediating role between knowledge management practices and innovation Egena et al. ${ }^{6}$ Through the application of knowledge, organizations can find sources of competitive advantage by offering knowledge integration methods to solve organizational problems Shin et al. ${ }^{18}$

Knowledge management is important to be implemented, if knowledge management in health services is not implemented properly it can cause the development of innovation to not run properly, and impacts such as reduced income flow, no increase in quality and staff satisfaction, which has an impact on decreasing customer satisfaction. healthcare patients can occur.

\section{Conclusion}

This study is that there is an effect of knowledge generation, knowledge storage, knowledge diffusion, and knowledge application on improving service innovation at Dental Hospital Hasanuddin University. Knowledge generation has 
influence and knowledge application has the lowest effect. Based on the research results and conclusions that have been formulated, it is suggested that hospital management pay more attention to knowledge applications at the Dental Hospital Hasanuddin University, because knowledge applications hospital can solve problems faced in service innovation.

\section{Acknowledgment}

Thank you for the support at Dental Hospital Hasanuddin University.

\section{Conflict of Interest}

The authors report no conflict of interest.

\section{References}

1. Padma, Rajendran, Lokachari. Service quality and its impact on customer satisfaction in Indian hospitals-Perspectives of patients and their attendants. Benchmarking: An Int J 2013;17: 807- 841 .

2. Mardani A, Nikoosokhan S, Moradi M, et al. The relationship between knowledge management and innovation performance. J High Tech Manag Res 2018;29: 12- 26.

3. Donate MJ, Guadamillas F. Organizational factors to support knowledge management and innovation. J Knowledge Manag 2011;15: 890- 914.

4. Donate M, Pablo JS. The role of knowledge-oriented leadership in knowledge management practices and innovation. J Business Res 2015;68: 360- 370.

5. Darroch J, McNaughton R. Examining the link between knowledge management practices and types of innovation. J Intellectual Capit 2002;3: 210- 222.

6. Egena O, Rajenthyran A. The mediating role of knowledge application in the relationship between knowledge management practices and firm innovation. J Inn Knowledge 2020;5: 210- 218.
7. Costa V, Monteiro S. Key knowledge management processes for innovation: A systemicy literature review. VINE J Information Knowledge Manag Systems 2016;46: 386- 410

8. Wang KL, Chi Chiang, Chiu-Mei Tung. Integrating human resource management and knowledge management: from the view point of core employees and organizational performance. Int J Org Inn 2012;5: 109- 137.

9. McCann JE, Buckner. Strategically integrating knowledge management initiatives. J Knowledge Management 2004;8: 47- 63 .

10. Williams P, Sullivan H. Lessons in leadership for learning and knowledge management in multi- organizational settings. Int J Leadership in Public Services 2011;7: 6- 20.

11. Xie X, Wang L, Zeng S. Inter-organizational knowledge acquisition and firm's radical innovation: A moderated mediation analysis. J Business Res 2018;90: 295- 306.

12. Alegre J, Sengupta K, Lapiedra R. (2013). Knowledge management and innovation performance in a high-tech SMEs industry. Int Small Business J 2013;31: 454- 470.

13. Yung-Lung Lai, Maw-Shin Hsu, Feng-Jyh Lin, et al. The effects of industry cluster knowledge management on innovation performance. J Business Res 2014;67: 734- 739.

14. Hamdoun M, Chiappetta JCJ, Ben-Othman H. Knowledge transfer and organizational innovation: Impacts of quality and environmental management. J Cleaner Produc 2018;193: 759- 770.

15. Cheng MY, Ho JSY, Lau PM (2009). Knowledge sharing in academic institutions: A study of Multimedia University Malaysia. Electronic J Knowledge Manag 2009;7: 313- 324.

16. Abou ZES. A Knowledge Management Reference Model. J Knowledge Manag 2002;6: 486- 499.

17. Boateng H, Agyemang FG. The effects of knowledge sharing and Knowledge Application on service recovery performance. Business Information Rev 2015;32: 119- 126.

18. Shin M, Hoden T, Schmidt RA. From knowledge theory to management practice: Towards an integrated approach. Information Process Manag 2001;37: 335- 355.

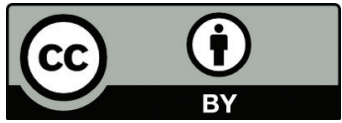

This work is licensed under a Creative Commons Attribution 